\title{
¿POR QUÉ IMPORTA LA FILOSOFÍA HOY? A PROPÓSITO DE UNA PROPUESTA DE CARLOS PEÑA
}

\author{
Jaime Araos San Martín \\ Universidad de Chile / Universidad Andrés Bello \\ jaimearaoz@gmail.com
}

\begin{abstract}
$\overline{R M}$
No es necesario hablar de filosofía para hacer filosofía. Es más, puede suceder que hablando de ella se disimule que se ha escurrido como el agua entre los dedos, y en su lugar ha aparecido la historia, la ideología o la cháchara. Ello puede ocurrir porque el asunto de la filosofía no es la filosofía; ella no se constituye respecto de un objeto -su objeto es cualquier cosa-, sino respecto de un modo de preguntar y de considerar las cosas, respecto de una actitud de vida y respecto de un amor y una pasión. Para fortuna nuestra, esta noble disciplina no se escurre del pensamiento que expone Carlos Peña tanto en el encuentro que recogen estas páginas como en su reciente libro Por qué importa la filosofía (2018). El autor habla filosóficamente de la filosofía, ayudado seguramente por el entrenamiento de años en los que se ha caracterizado por aplicar un enfoque filosófico a sus análisis de los sucesos de interés público en los distintos medios. En las palabras que siguen, tengo en cuenta tanto el libro como la exposición de su autor en este encuentro.
\end{abstract}

En mi opinión, estamos ante una reflexión lúcida y rigurosa, que escapa de los lugares comunes para defender la filosofía, con exquisito cuidado y respeto, de toda instrumentalización y servicio a fines ajenos, que la destruirían. La argumentación se apoya en un rico aparato crítico. Desfilan en su composición importantes nombres del pensamiento moderno y contemporáneo: ante todo, Heidegger, Ortega y Gasset, Wittgenstein, Kant; pero también, Weber, Husserl, Frege; y a continuación, Russell, Rorty, Sartre, Berlin, Luhmann, Millas, Searle, entre otros. Podría parecer que ingredientes tan heterogéneos darían lugar a un discurso abigarrado y difícil de seguir. No es así. Pues el autor, en busca de respuesta a las preguntas que se plantea, logra cavar hasta la raíz de esos pensamientos tan distintos, para hallar, sin forzarlos y de un modo sorprendentemente convincente, una unidad fundamental (iphilosophia perennis?), que vierte en un texto claro y bien escrito. Pienso que el libro podría ser una excelente introducción a la filosofía.

Me enfoco a continuación en algunos puntos neurálgicos. Etimológicamente, importar es "llevar hacia nosotros". Importante es lo que lleva hacia nosotros algo valioso. ¿Qué lleva hacia nosotros la filosofía? La respuesta depende, evidentemente, de lo que se entienda por filosofía. ¿Qué es, pues, filosofía? Cuando el autor quiso responder a esta pregunta de un modo muy conciso escogió proceder dialécticamente, trayendo a presencia el frente polémico representado por una tesis de Bertrand Russel: 
ciencia es lo que más o menos sabemos; filosofía es lo que no sabemos ${ }^{1}$. Peña opina que el concepto de Russell ha de tomarse en serio porque tiene a su favor el hecho innegable de que históricamente las distintas ciencias se han ido desprendiendo e independizando, en efecto, de la filosofía; y esto significa, como lo subraya el mismo Russell, que cada avance de la ciencia le roba a la filosofía preguntas que alguna vez le pertenecieron. La suerte de la filosofía está echada: ha de quedarse sin objeto propio - sin un campo epistémico- y sin nada que decir: muda. En tal caso, obviamente, la filosofía no importará nada, porque no tendrá nada valioso que llevar hacia nosotros. Y entretanto, no puede aportarnos otra cosa que el encanto y la entretención de la libertad especulativa y el juego de las opiniones contrapuestas (Russell 2010, 124).

Quisiera detenerme en la tesis de Russell. Esta pasa por alto algunas cosas que no debería. Primero, situar la filosofía en el campo de lo que no se sabe $<$ científicamente $>$, es tan erróneo como situarla en el campo de lo que se sabe <científicamente>. El reductivismo y simplificación excesiva de su mirada le impiden hacer pie en ese otro espacio fundamental que descubrió y conquistó Sócrates: la filosofía es el saber del no saber (Apología 21d, 23 b, 29a-b)². Ella no se da en el saber ni el no saber, sino "entre" uno y otro, en el intersticio. Porque es saber del no saber, la filosofía únicamente toma forma y se constituye en el preguntar. El preguntar no se puede dirigir a lo que no se sabe, puesto que no se sabe, ni mucho menos a lo que se sabe, puesto que se sabe ${ }^{3}$. El preguntar filosófico se dirige al intersticio, donde busca aquello que no es ni puede ser objeto (positum), pero hace posible a los objetos, como la luz a lo visible, para emplear una imagen platónica. Aquello, lo que está latente, lo no pensado, lo que no admite la objetivación porque no está allí al frente, sino subyacente envolviéndolo todo, aquello que Platón y Aristóteles y Agustín y Tomás de Aquino y Heidegger han llamado el ser, eso es aquello por lo que se pregunta la filosofía ${ }^{4}$. Y porque la filosofía se constituye en el preguntar, se prolonga naturalmente en el diálogo, del cual Sócrates es, nuevamente, el maestro. El diálogo tiene como condición de posibilidad que la verdad es un bien común, más precisamente, algo que nadie tiene, sino en lo que se está y se comparte ... e intersubjetivamente se busca. La petulancia de la verdad como un bien privado que puede ser posesión de uno o unos pocos es una invención sofística y gnóstica.

Segundo, la conexión entre ciencia y filosofía parece ser bastante más íntima, rica y compleja que la descrita por Russell. Una mirada unilateral hacia el pasado remoto puede arrojar, seguramente, esa concepción de la filosofía como madre de las

1 "I think perhaps that is true, but I believe the only difference between science and philosophy is, that science is what you more or less know and philosophy is what you do not know. Philosophy is that part of science which at present people choose to have opinions about, but which they have no knowledge about. Therefore every advance in knowledge robs philosophy of some problems which formerly it had" (Russell 2010, 124).

He desarrollado más esta interpretación en Araos 1999.

Escribo esto teniendo en mente el argumento erístico que discute Platón en Menón 80d-e. Carlos Peña ha hecho de esta tesis un eje central de su propuesta filosófica, como se verá más abajo. 
ciencias, una madre que resulta abandonada y unas ciencias huérfanas, en el transcurso de una evolución imaginada por Comte desde la etapa metafísica a la positiva. Pero una mirada ampliada hacia el pasado próximo y el presente inmediato - mirada que ya se podía realizar en 1918, cuando Russel publica el libro citado-, descubre algo muy diferente: la filosofía no deja de ser madre, pero pasa a ser también hija de la ciencias. En efecto, los nuevos conocimientos vienen a ser nuevos motivos de interrogación y de reflexión filosófica, como es patente en el caso de los descubrimientos y teorías de la astronomía, la medicina, la biología, la física, la psicología, las matemáticas, etc. Es más: pertenece al propio dinamismo y progreso de una ciencia que sus cultores más avanzados pasen a interrogarse sobre la validez de sus métodos, los límites de su campo epistémico, la naturaleza de su objeto y de sus supuestos, la solidez de sus leyes, las consecuencias éticas y políticas de sus descubrimientos, la intersección e interrelación con otras ciencias, etc., cuestiones todas que sobrepasan el campo de una ciencia particular y vienen a ser estrictamente filosóficas. El científico se llega a plantear estas cuestiones no por razones personales o incidentales - que pueden intervenir-, sino por la misma cientificidad que lo mueve a hacer ciencia hasta el límite y sobrepasarlo. Para entrar en la filosofía el científico no necesita tanto los títulos como las preguntas adecuadas. Peña explica detalladamente, por ejemplo, cómo ello se dio así con Frege y Husserl, a partir de las matemáticas. Y podemos prever que este fenómeno se dará cada vez con mayor frecuencia desde el momento en que constatamos cómo cada avance en la investigación está produciendo muchas más preguntas que respuestas, hasta el punto de que podemos considerar que ya no son éstas, sino más bien aquellas el patrimonio de una ciencia.

Tercero, no sé hasta qué punto Russell tuvo conciencia de que su tesis "ciencia es lo que sabemos; filosofía, lo que no sabemos", no es una afirmación científica, sino filosófica; por tanto, de acuerdo a su propio criterio, algo que "no sabemos". Posiblemente lo advirtió, pero, como los otros positivistas lógicos de la primera mitad del siglo XX, no llegó a comprender a tiempo su más grave implicación: la negación de la filosofía no puede llevarse a cabo sino haciendo filosofía. Tendría que decirse de ésta, aquello que el agudo Gómez Dávila dice de la metafísica: “Tan repetidas veces la han enterrado que hay que juzgarla inmortal” (Gómez Dávila 1954, 333).

Vuelvo a la pregunta primera. Si la filosofía no es ese concepto negativo y residual que opinaba Russell ¿qué es y cuál el valor que comporta para nosotros? C. Peña pasa revista a las tendencias contemporáneas que quisieron salvar a la filosofía reservándole un lugar por encima de la ciencia. Así, el neokantismo, que se da a la tarea de acreditar las posibilidades epistémicas de la ciencia; el positivismo lógico y la filosofía analítica, que asumen la misión de evaluar el lenguaje de la ciencia; y el fundacionalismo, que se atribuye la capacidad de fundamentar la ciencia y la cultura. Sin embargo, el autor rechaza la pretensión de dar a la filosofía el papel de legisladora, jueza y supervigilante de la ciencia y la cultura; ninguna de estas corrientes, según él, logra identificar aquello valioso que únicamente la filosofía puede llevar hacia nosotros. Tampoco le parece satisfactoria, con justa razón, la respuesta que ofrece, en el extremo 
opuesto, el relativismo posmoderno, como el de Rorty. Este pierde de vista lo específico de la filosofía y tiende a confundirla casi con la literatura (Peña 2018, 181) .

Lo que estamos buscando lo halla C. Peña sobre todo en la concepción heideggeriana de la filosofía como "ciencia originaria". De acuerdo con ésta, su tarea "consiste en retroceder todas nuestras concepciones a la estructura que las hace posible [...] mostrando de paso que todas esas concepciones son contingentes [...], una tarea que introduce una muy radical reflexividad a nuestro quehacer y a nuestra cultura. Y quizás ahí radique la novedad y la importancia de la filosofía. Y es que sin ella, la cultura sería mera afirmación y nunca duda" (83). Por esa estructura originaria y de carácter ontológico el ser humano está entreverado con la realidad, pero al mismo tiempo en la experiencia de insuperable distancia respecto de ella, puesto que no se nos da nunca en su pura desnudez, sino siempre interpretada - "disfrazada", también dice $\mathrm{C}$. Peña- conforme a alguna determinada comprensión del ser, que es histórica y contingente. Ahora bien, toda comprensión del ser tiende a absolutizarse e imponerse no como una interpretación posible entre otras, sino como el ser mismo. En cada época, en cada cultura, en cada mundo tiende a producirse este olvido de su origen contingente e histórico, que lleva a la absolutización de su comprensión del ser. La filosofía es el único sector en toda la cultura que puede curar de este olvido regresando hasta la estructura que la hace posible; retrocediendo hasta el intersticio, como lo he llamado yo, entre lo conocido y lo no conocido donde se descubre el mundo y la cultura en su dramática finitud y contingencia; despensando lo pensado para caer en la cuenta de lo no pensado y subyacente. Despensar, así podríamos resumir en una palabra -en la palabra que empleó Ortega para referirse a una conferencia de Heidegger en el Coloquio de Darmstad-, la tarea propia de la filosofía. “ ¡El mundo -exclamó entonces Ortega, como recuerda C. Peña (188)- necesita de los despensadores para que los demás animales no se duerman!"6.

Ahora bien, el hechizo hipnótico y amnésico de cada cultura se da con una fuerza arrolladora, quizás irresistible, como nunca antes se vio, en la "época de la imagen del mundo", es decir, en la época de la técnica, donde todo aparece como material de explotación, como recurso, y su valor se mide únicamente en función de la utilidad. La absolutización creciente de esta comprensión del ser no está dejando espacio alguno para recordar en nuestra cultura que ella es producto de una red de significados, de un mundo que corresponde a una interpretación del ser posible entre otras, tan contingente e histórica como otras. Esta absolutización de la cultura con un completo olvido del sentido la transforma en una jaula de hierro, como afirma Weber. De allí que se dé la paradójica situación en nuestra época de una cultura que necesita como nunca de la filosofía para que alumbre su origen, el intersticio que la ha hecho posible, y a la vez,

5 Este relativismo, añade Peña, "tranforma la institución universitaria [...] en un instrumento maleable destinado a expandir y hacer hegemónicos ciertos puntos de vista donde la lucha por el currículum no es una preocupación por el saber, sino un esfuerzo por instrumentalizar el trabajo de la universidad".

6 Cf. M. Heidegger 1983, pp. 141-44. 
haga todos los esfuerzos para desalojarla como una actividad inútil y molesta, en la medida en que se mantiene indócil y no sirve a ningún propósito técnicamente valioso.

En este momento de su andadura, me parece que el autor ya no puede seguir en la compañía de Heidegger. En efecto, C. Peña quiere que la filosofía cumpla el papel de hacer patente la condición contingente de la época de la técnica, para que podamos sacudirnos, si no de ella, al menos de su hechizo. Pero ¿hasta qué punto es esta época contingente, según Heidegger? ¿Cómo se concilia la afirmación de la contingencia con la afirmación de la historia de la metafísica como historia del olvido del ser (Heidegger 1997, §6) y con su afirmación del lógos griego como prefiguración de la técnica, del cual no sería más que su despliegue en el tiempo? (Heidegger s.d., 161-64).¿No es la "época de la imagen del mundo", para Heidegger, el destino de la cultura occidental, que ahora se ha hecho planetaria? (Heidegger 2012). Y si no fuera así ¿cómo entender el sentido de su conferencia "El final de la filosofía y la tarea del pensar"? (Heidegger 2000, 77-94) ¿No es acaso una declaración de la impotencia de la filosofía en este mundo de la técnica, y su llamado a sustituirla por el "pensar poético"? ¿No está implicada su convicción sobre esta impotencia en la sombría declaración que hace a Der Spiegel: "Sólo un dios podría salvarnos"? La lectura en profundidad, pero optimista de Heidegger que hace C. Peña, le permite reconocer y salvar razonablemente algunos de estos escollos (cf. p. 20), pero no le permite de igual modo, me parece, desconocer el profundo pesimismo en el cual cae el pensador germano, sobre todo en el último período de su vida, acerca de lo que puede hacer la filosofía con nosotros. Yo creo que en este punto se puede estar con C. Peña y su reivindicación de esta disciplina, pero no (tanto) con Heidegger.

Para terminar, quisiera dar un último apriete a la pregunta de fondo: ¿por qué importa la filosofía, según C. Peña? ¿qué es aquello valioso que trae hacia nosotros? Libertad. Me parece que esta palabra resume el núcleo de su propuesta. Libertad ¿en qué sentido? En varios. Repasemos lo ya dicho. Por un lado, la filosofía es una cura del olvido, liberación de la amnesia que se produce (sobre todo) en la época de la técnica acerca del sentido. La filosofía es, al contrario, anámnesis (Platón), recuerdo de la verdad olvidada: que lo útil no es útil sino a causa de la finalidad, del para-qué en razón del cual cobra significado y valor. La filosofía tiene la función de oponerse al absolutismo de lo útil y liberar a la cultura del sinsentido, de la profunda insensatez que se sigue del aprehender la realidad con la mirada del pirata: con un ojo ver nada más su valor de explotación y utilidad; con el otro, implantarse un parche para no ver y olvidar recalcitrantemente el ser de donde proviene todo su sentido e importancia, y la irritante filosofía, que le enrostra el reino de los fines.

Por otro lado, es una cura del sueño y la superstición, liberación del estado hipnótico en que cae el ser humano en el mundo moderno a causa del hechizo de la ciencia y la técnica y su absolutización de lo útil. El tábano de la filosofía lo despierta con su picadura, retrocediendo su atención al intersticio entre lo conocido y lo no conocido, donde aparece el mundo en toda su contingencia y finitud, su petulancia e ilusoriedad. Y así lo sacude de su modorra, para que vuelva a tomar la iniciativa y se reconozca como lo que es: no solo un habitante, sino un abridor de mundo; la libertad de pensamiento deviene libertad de acción. Como recuerda Peña (183), un papel análogo 
es el que asigna Kant a la facultad de filosofía con respecto a las facultades superiores -teología, derecho y medicina- en la universidad: “ no [...] destruir sus doctrinas, sino sólo [...] negar esa fuerza mágica que la superstición del público les atribuye a ellos y a sus respectivas observancias, como si al entregarse pasivamente a guías tan hábiles se estuviera dispensando de toda acción personal"(Kant 2004, p. 40).

Finalmente, la filosofía puede poner en cuestión lo útil, alcanzar su comprensión y revelar su contingencia y futilidad -su patético absurdo en tanto que separado del sentido que le da origen- porque su esencia no es la utilidad, sino la libertad. La libertad es el único elemento en el que ella puede vivir, crecer y desplegarse (Aristóteles) ${ }^{7}$. La filosofía, escribe C. Peña en términos de Kant, es inútil “en la medida que no está al servicio de ningún designio más que el sometimiento a la mera racionalidad" (183). Esta exigencia de libertad se sostiene sin concesiones de ninguna especie. Por eso, no es aceptable ponerla al servicio de ningún poder, ni siquiera al servicio de la democracia, como quiere Rorty (181), por más que sea manifiesta la necesidad que tiene ésta de aquella.

Decía al comienzo que no es necesario hablar de filosofía para hacer filosofía, porque no es ésta el asunto de la filosofía. De allí no se sigue, sin embargo, que no pueda ésta caer en su campo. De hecho, cada cierto tiempo la filosofía también tiene necesidad, como ninguna otra disciplina intelectual, de volver sobre sí misma y devenir objeto de reflexión ${ }^{8}$. La filosofía es también asunto de la filosofía. Es de agradecer no solo de parte de los filósofos y profesores de filosofía, sino de los universitarios y de toda la cultura que el autor nos haya invitado, con profundidad y sencillez, a reflexionar y dialogar sobre lo no pensado.

\section{Referencias bibliográficas}

Araos, Jaime (1999), "La invención de la escritura y la musa de la filosofía”, Silencio, palabra y acción, Santiago: Centro de Estudios Clásicos UMCE, 137-150.

Calonge, Julio (2008), Apología, en Platón, Diálogos I. Madrid: Gredos.

7 "Es pues evidente que no buscamos la filosofía por su utilidad, sino que, así como llamamos libre al que es para sí mismo y no para otro, así consideramos a ésta como la única ciencia libre, pues esta sola es para sí misma [...] Así, pues, todas las ciencias son más necesarias que ésta; pero mejor, ninguna" (Aristóteles, Met. I 2, 982b24-983a11). Peña encuentra esta tesis fundamental en Heidegger: "La filosofía, Heidegger declara, es un saber inútil pero, agrega, señorial" (29). Como es sabido, éste dirá, en un sentido no muy lejano, que "la esencia de la verdad es la libertad" (2001, §4-5).

8 Esta es una de la exigencias de la "filosofía primera", según Aristóteles, en cuanto investigación de "lo primero", y por tanto, de lo "supuesto"(hypóthesis), de aquello que suponen las ciencias particulares y de lo que arrancan sus razonamientos, pero no pueden hacerse cargo, porque excede su campo. El saber filosófico, en cambio, no puede erguirse sobre supuestos, es "anypótheton" (Met. IV 3, 1005b14), y por tanto, es tarea suya volver sobre sí misma para conocerse. 
García Yebra, V. (1970), Metafísica de Aristóteles. Madrid: Gredos, versión trilingüe. Gómez Dávila, Nicolás (1954), Notas. México, edición privada. Hay una edición más reciente a cargo de Franco Volpi. Bogotá 2003: Villegas Editores.

Gómez-Lobo, Alfonso (2002), Platón, Menón. Santiago: Editorial Universitaria. Es útil también la versión bilingüe de Antonio Ruiz de Elvira (1986), Madrid:Centro de Estudios Constitucionales.

Heidegger, Martin (1983), "Encuentros con Ortega y Gasset," Revista de Filosofía, (vol. 21) 141-44.

(1997), Ser y tiempo, traduc. Jorge Edo. Rivera. Santiago: Editorial Universitaria.

(s.d.), Doctrina de la verdad según Platón (trad. L. García Bacca) y Carta sobre el humanismo (trad. A. Wagner de Reyna). Santiago: Centro de Estudios Humanísticos y Filosóficos, Universidad de Chile.

(2000), "El final de la filosofía y la tarea del pensar", Tiempo y ser. Madrid: Tecnos, 77-94.

(2001), "De la esencia de la verdad", Hitos. Madrid: Alianza, 151-72.

(2012), "La época de la imagen del mundo", Caminos de bosque, trad. Helena Cortés y Arturo Leyte. Madrid: Alianza, pp. 63-78.

Kant, Immanuel (2004), El conflicto de las Facultades. Buenos Aires: Losada.

Peña, Carlos (2018), Por qué importa la filosofía. Santiago: Taurus.

Russell, Bertrand (2010), The Philosophy of Logical Atomism. London y New York: Routledge, 2010. La edición original es de 1918. 